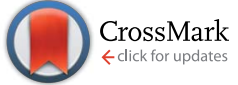

Cite this: RSC Adv., 2014, 4, 35678
Received 19th May 2014

Accepted 18th July 2014

DOI: $10.1039 / c 4 r a 04715 j$

www.rsc.org/advances

\title{
Controlled deposition of magnetic particles within the 3-D template of wood: making use of the natural hierarchical structure of wood
}

\author{
Stacy Trey, ${ }^{\star a b}$ Richard T. Olsson, ${ }^{c}$ Valter Ström, ${ }^{d}$ Lars Berglund ${ }^{\text {bc }}$ \\ and Mats Johansson ${ }^{b c}$
}

\begin{abstract}
This study presents a promising method to make three-dimensional lattices of structured nanomaterials by using wood templates for in situ (confined) directed growth of inorganic material in the ordered cell walls. The wood was impregnated by transition metal ion precursors (iron, manganese and cobalt) at 5 bars pressure that were further transformed into magnetic particles $\left(\mathrm{Fe}_{3} \mathrm{O}_{4}, \mathrm{MnFe}_{2} \mathrm{O}_{4}\right.$ and $\left.\mathrm{CoFe}_{2} \mathrm{O}_{4}\right)$ by addition of alkaline solutions. It was found that by this method, it was possible to produce lightweight ferromagnetic functionalized wood materials in an inexpensive and environmentally friendly way. It was possible to functionalise the wood throughout the structure with a high weight percent of particles from 15-20 wt\% as observed by TGA. These were not only adsorbed to the surface of the lumen, but also found by SEM-EDX throughout the cell wall and middle lamella and in higher amounts in early wood. The magnetic properties were nearly unaffected by the incorporation into the wood samples as compared to powder compacts obtained as particles that precipitated separately in the impregnation solution, both for soft and hard magnetic materials. Whereas the hard magnetic phase $\mathrm{CoFe}_{2} \mathrm{O}_{4}$ showed insignificant leaching, the soft magnetic $\mathrm{Fe}_{3} \mathrm{O}_{4}, \mathrm{MnFe}_{2} \mathrm{O}_{4}$ lost around 50 wt\% during repeated washing in deionized water, suggesting that the $\mathrm{CoFe}_{2} \mathrm{O}_{4}$ particles were more readily attached in the structure of the wood. The crystal structure of the magnetic particles was determined to be the same in the wood structure as those formed in solution.
\end{abstract}

\section{Introduction}

Magnetic materials such as those based on ferrite are widely used in applications such as information data storage, drug delivery, magneto-optical devices, actuators, and anti-radar detection/radio frequency materials. ${ }^{1-3}$ Most of these materials are prepared at sintering temperatures above $1000{ }^{\circ} \mathrm{C} .{ }^{4}$ and the required energy input for their manufacture is high. However, an increased attention has been directed towards soft chemistry 'chemi douce' routes for aqueous preparation of magnetic nanoferrites and the use of polymers that not only work as a adhesive and flexible matrix for the magnetic phase, but also prevent the magnetic phase from corroding. ${ }^{5,6} \mathrm{~A}$ hurdle has been to organize the inorganic nanoparticles into a uniformly distributed phase that can allow the organic polymer matrix to

\footnotetext{
${ }^{a}$ SP Technical Research Institute of Sweden, Department of Wood Technology, Drottning Kristinas väg 67, SE-114 28, Stockholm, Sweden.E-mail: stacy.trey@sp.se ${ }^{b}$ Wallenberg Wood Science Centre (WWSC), Teknikringen 56-58, SE-100 44 Stockholm, Sweden

${ }^{c}$ Department of Fibre and Polymer Technology, KTH - Royal Institute of Technology, Teknikringen 56-58, SE-100 44 Stockholm, Sweden

${ }^{d}$ Department of Materials Science and Engineering, KTH Royal Institute of Technology, Brinellvägen 23, SE-100 44 Stockholm, Sweden
}

retain its mechanical properties. ${ }^{7}$ Most often, magnetic particles blended with polymers in high amounts leads to brittle composites as a result of the non-uniform distribution of the particles in the polymers. ${ }^{8}$ The applications for this more ductile class of magnetic materials may include lowtemperature $\left(<200{ }^{\circ} \mathrm{C}\right)$ moulded alternatives to the above, but also porous counterparts such as membranes/filters for purification and filtration, separation of biochemicals, or magnetoacoustics purposes.9-11 Traditional methods for membrane and film manufacturing are time consuming and costly due to lack of robust preparation methods. These methods can include filling carbon nanotubes with iron oxide nanoparticles, lithographic methods, micro contact printing, and capillary filling. ${ }^{12-15}$ Further, slight variations in magnetic particle distribution and volume fraction in a matrix greatly affect the resulting bulk properties. ${ }^{16,17}$ In order to provide a lightweight and inexpensive 3-D matrix, Marchessault et al. combined commercial magnetic particles with chemically modified cellulose fibers in a lumen-loading process to produce magnetically responsive particles, fibers, and film materials. ${ }^{18,19}$ Recently, Olsson et al. precipitated magnetic particles in the presence of aerogels of cellulose nanofibrils (in situ) to produce 3-D templates with a unique set of characteristics such as high strength, light weight, and a high density of magnetic 
nanoparticles. ${ }^{20}$ Further work has been performed by Liu et al. to combine a large amount of magnetic particles with regenerated cellulose and burn away the cellulose to leave behind porous magnetic fibres in a well ordered pattern. ${ }^{21}$ Further, Ström and Olsson et al. have established the effect of reaction condition and correlation to size distribution and particle size to the method of precipitation of magnetite particles from an aqueous iron ion solution. ${ }^{22,23}$ In this context, the mechanical strength of wood that has a natural reinforcing yet light structure, and therefore is an ideal template to combine with magnetic nanoparticles to produce inexpensive, lightweight, and strong magnetic materials. Growth of magnetic nanoparticles within the wood structure is likely to form a 3-D ordered structure that is lightweight, does not deform upon the addition of water, and can be easily scaled-up. This concept was first presented by Trey et al. European Conference on Wood Modification 2012, where the low $\mathrm{pH}$ absorption of iron precursors into the porous hierarchical structure of wood was demonstrated. ${ }^{24}$ Further research on the subject was then published by Merk et $a .^{25}$

Herein we present the morphology of the particles in the wood structure and the characteristics of magnetic particle modified wood. Southern yellow pine (SYP) veneers (thin sections of wood) have been made magnetic by in situ precipitation of the magnetic particles in the wood structure. The morphology, magnetic character, thermal properties and crystal structures of the modified wood samples were characterized and are discussed. Not only, was the hierarchical architecture of the wood possible to utilize for even distribution of the impregnating water borne salt, but it also appeared confine the volumes of the precipitated materials and thereby influence the crystallization phenomena to an extent where the magnetic materials no longer resembled the commonly encountered morphologies obtained from classical precipitation reactions in absence of templates.

\section{Experimental}

\section{Materials}

Carolina Southern yellow pine wood veneers that were cut by the half-round slicing method were supplied by Capital Crispin Veneer (London). After conditioning at 65\% RH, the wood veneers had approximately $11 \mathrm{wt} \%$ moisture content and a density of $530 \mathrm{~kg} \mathrm{~m}^{-3}$. The metal salts, $\mathrm{CoCl}_{2}, \mathrm{FeSO}_{4}, \mathrm{MnCl}_{2}$, $\mathrm{NaOH}$, and $\mathrm{KNO}_{3}$ were used as received from Sigma Aldrich.

\section{Impregnation and magnetic particle precipitation procedure}

The wood veneers, prepared in sets of five, were cut to dimensions of $0.06 \times 5.0 \times 5.0 \mathrm{~cm}$. The wood samples were first placed under vacuum for 30 minutes to evacuate the air from the porous structures, and further pressure impregnated with $\mathrm{N}_{2}$ for $8 \mathrm{~h}$ at 5 bars.

The processing route is presented in Fig. 1.

The co-precipitation was performed with different amounts of metal salts and the target was $15 \mathrm{wt} \%$ loading of inorganic content to wood material. The ratio $\left[\mathrm{Me}^{2+}\right] /\left[\mathrm{OH}^{-}\right]$and

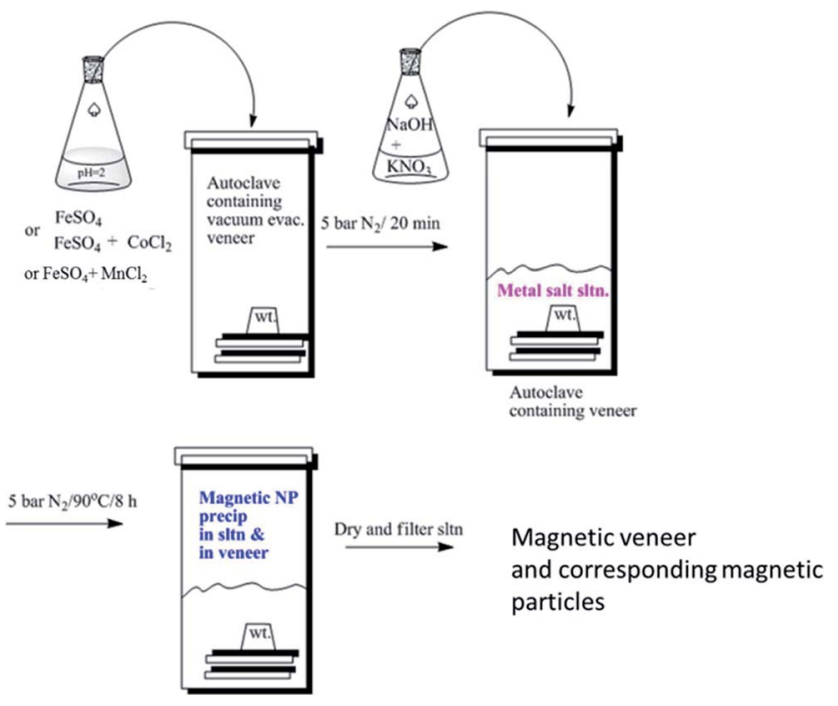

Fig. 1 Overview of the process for fabrication of magnetic particle modified wood veneers.

$\left[\mathrm{Me}^{2+}\right] /\left[\mathrm{KNO}_{3}\right]$ were kept constant and equal to $1 / 2$ and $1 / 3$, respectively. An example formula is as follows: $2.1 \mathrm{~g}(7.7 \times$ $10^{-3}$ moles) of iron(II) sulphate heptahydrate $\left(\mathrm{FeSO}_{4} \cdot 7 \mathrm{H}_{2} \mathrm{O}\right)$ was combined with $1.52 \mathrm{~g}\left(7.7 \times 10^{-3}\right.$ moles $)$ of manganese(II) chloride $\left(\mathrm{MgCl}_{2}\right)$ or with $1.8 \mathrm{~g}\left(7.7 \times 10^{-3}\right.$ moles $)$ of cobalt(II) chloride $\left(\mathrm{CoCl}_{2} \cdot \mathrm{H}_{2} \mathrm{O}\right)$ in $200 \mathrm{ml}$ of water. This solution was decreased in $\mathrm{pH}$ with a $1 \mathrm{M}$ solution of sulphuric acid to $\mathrm{ca} .2$ to avoid iron oxide precursor particle formation prior to complete impregnation or absorption of the solution in the wood samples. ${ }^{26}$ The solution was then added to the air evacuated wood samples in the $1 \mathrm{l}$ autoclave and pressure was applied for 20 minutes at 5 bars. Next, $150 \mathrm{ml}$ of water was combined with $1.8 \mathrm{~g}\left(4.6 \times 10^{-2}\right.$ moles $)$ of $\mathrm{NaOH}$ and $3.5 \mathrm{~g}\left(3.5 \times 10^{-2}\right.$ moles $)$ of potassium nitrate $\left(\mathrm{KNO}_{3}\right)$ and added to the autoclave, placed under pressure ( 5 bar), and placed in a water bath at $90{ }^{\circ} \mathrm{C}$ for $8 \mathrm{~h}$. The modified wood was then removed from solution and rinsed with distilled water in order to remove surface growth and debris. The wood samples were then placed in a vacuum oven at $50{ }^{\circ} \mathrm{C}$ for $24 \mathrm{~h}$. The aqueous solution was then decanted from particles that had formed separately in the reactor and dried in an oven at $103{ }^{\circ} \mathrm{C}$ for $24 \mathrm{~h}$. The inorganic content of the wood was measured gravimetrically. An additional sample was prepared for optical microscopy, with half the target concentration, i.e. $8 \mathrm{wt} \%$.

\section{Dimensional stability, equilibrium water uptake, and leaching evaluation}

The samples were first conditioned at 65\% RH before leaching experiments. The weight and dimensions were measured with a slide calliper at midpoints of the sample in order to take an initial weight and volume measurement of the specimens. The samples were then placed in the impregnation solution. After being taken out of solution, the weight and dimensions were taken in order to determine the degree of swelling and water uptake of the specimens in the different solutions. This 
measuring was also performed after drying the impregnated samples in order to determine the weight percent of particles taken up by the wood specimen and if the particles had filled the pores of the wood cell wall which would be observed by increased dry volume of the samples. This allowed for calculation of the uptake of the impregnation solution, bulking or volume swelling from polymer uptake. ${ }^{27}$ Leaching studies were done on all samples according to the EN-84 standard over 14 days, in which the samples are submerged in a fixed volume ratio of water to sample, the samples are vacuum evacuated of air, and the water changed out every day for 12 of the 14 days (EN-84:1997). ${ }^{28}$ This standard is typically used on modified wood to determine the degree of permanence of a modification method and whether the additives used in modification could leach out into the surrounding environment, information of particular importance for modified wood that may be exposed to exterior (outdoor) applications. The weight loss of the modified samples after 14 days in water and after oven drying was measured by thermo gravimetric analysis (Table 1 ).

\section{Thermogravimetric analysis (TGA)}

Samples from the different membranes were analysed in a Mettler-Toledo thermogravimetric analyzer (TGA/SDTA851) under a $50 \mathrm{ml} \mathrm{min}{ }^{-1} \mathrm{O}_{2}$ flux. The heating rate was $10{ }^{\circ} \mathrm{C} \mathrm{min}^{-1}$ from 30 to $750{ }^{\circ} \mathrm{C}$.

\section{Scanning electron microscopy (SEM) and energy-dispersive X-ray spectroscopy (EDX)}

The morphology of wood sectioned by laser-cut and tension fracture were observed in a Field-Emission Scanning Electron Microscope (SEM) (Hitachi, Japan). A nanometer thin (surface sputtered for $25 \mathrm{~s}$ ) gold-palladium layer (Cressington 208HR, UK) was applied to the samples to minimize electrical charging. Cross sections of the wood veneer samples were also analyzed by scanning electronic microscopy (SEM, Jeol JSM-6400) coupled with energy dispersive X-ray analysis (EDX). The elemental data was collected from areas of $500 \mathrm{~nm}$ in diameter.

\section{Laser cutting technique}

The samples were ablated transverse and along the fibre direction to give a cross section using a pulsing UV (KrF) exciplex laser (Lumonix 600LX) of radiation emission of $248 \mathrm{~nm}$. The irradiation energy was $375 \mathrm{~mJ}$, the pulse width was $20 \mathrm{~ns}$, and the pulse frequency was $3 \mathrm{~Hz}$.

\section{Optical microscopy}

An Olympus BX51 Optical microscope with AnalySIS Five digital imaging solutions software was used to observe cross sections of the wood veneer samples.

\section{Magnetic characterization}

Magnetic characterisation was performed in a vibrating sample magnetometer (VSM, Oxford Instruments, UK). The applied field strength was varied in the range $\pm 500 \mathrm{kA} \mathrm{m}^{-1}$ and the measurements were performed on thin strips of the prepared
Table 1 Sample naming scheme

\begin{tabular}{ll}
\hline Sample Name & Description \\
\hline $\begin{array}{l}\mathrm{Me}_{3} \mathrm{O}_{4} \text {-particles } \\
\mathrm{MnFe}_{2} \mathrm{O}_{4} \text {-particles }\end{array}$ & $\begin{array}{l}\mathrm{Fe}_{3} \mathrm{O}_{4} \text { particles precipitated in } \\
\text { solution (not adhered to wood) } \\
\mathrm{MnFe}_{2} \mathrm{O}_{4} \text { particles precipitated } \\
\text { in solution (not adhered to wood) } \\
\mathrm{CoFe}_{2} \mathrm{O}_{4} \text { particles precipitated in } \\
\text { solution (not adhered to wood) }\end{array}$ \\
& \\
$\mathrm{CoFe} \mathrm{O}_{4}$-particles & $\begin{array}{l}\text { Unmodified wood } \\
\text { Particle impregnated wood with } \\
\text { magnetic particles to wood ca. }\end{array}$ \\
$\mathrm{v}-\mathrm{Fe}_{3} \mathrm{O}_{4}$ & 15 to 20 wt\%, before EN-84 leaching \\
$\mathrm{v}-\mathrm{MnFe}_{2} \mathrm{O}_{4}$ & of the wood sample \\
$\mathrm{v}-\mathrm{CoFe}_{2} \mathrm{O}_{4}$ &
\end{tabular}

membranes or on powder compacts initially demagnetised. Data was normalised to the mass of nanoparticles (derived from TGA analysis).

\section{X-ray diffraction}

X-ray diffraction was performed on a PANalytical X'pert Pro MPD. For all measurements, $\mathrm{Cu}-\mathrm{K} \alpha$ radiation $(\lambda=1.5417 \AA)$ was used. Due to the strong fluorescence of the ferrite, a setup with parabolic mirror and secondary monochromator was used. The analyses were done on the unaltered diffraction patterns, i.e. no smoothing or background correction was performed. All data collections were performed at ambient temperature (299 K).

\section{Results and discussion}

\section{Morphology of the modified wood specimens}

To evaluate the morphology of the particles in the wood structure and assess if there was a gradient in the concentration of particles as a result of the impregnation process, optical microscopy was used to image the cross section of the untreated ( $\mathrm{v}-\mathrm{U})$, half target concentration and full target concentration samples $\left(\mathrm{v}-\mathrm{Fe}_{3} \mathrm{O}_{4}\right)$, Fig. 2. It can be observed in the untreated wood veneer sample (v-U) that the empty pores or lumen appear white, with the cell wall surrounding these pores in a hexagonal structure, and linking the cell walls is the middle lamella (Fig. 2a). The different regions of more dense wood structure is the late wood (slower growth in the late summer to winter) and the more porous area (due to faster growth in the spring and early summer), is the early wood and together these make up an annual ring of the wood. The resin duct and ray are porous parts of the wood anatomy that have a transport function. For the impregnated samples, it appears that the structure of the wood lumens remain relatively free of particles with the addition of magnetic particles, as can be observed by the remaining porous structure of the wood (Fig. 2b and c). Further, the black colouration of the wood structure appears homogeneous throughout the cross section and indicates the presence of the magnetic particles in both the cell wall and middle lamella. This dark color is more intense for the high concentration 

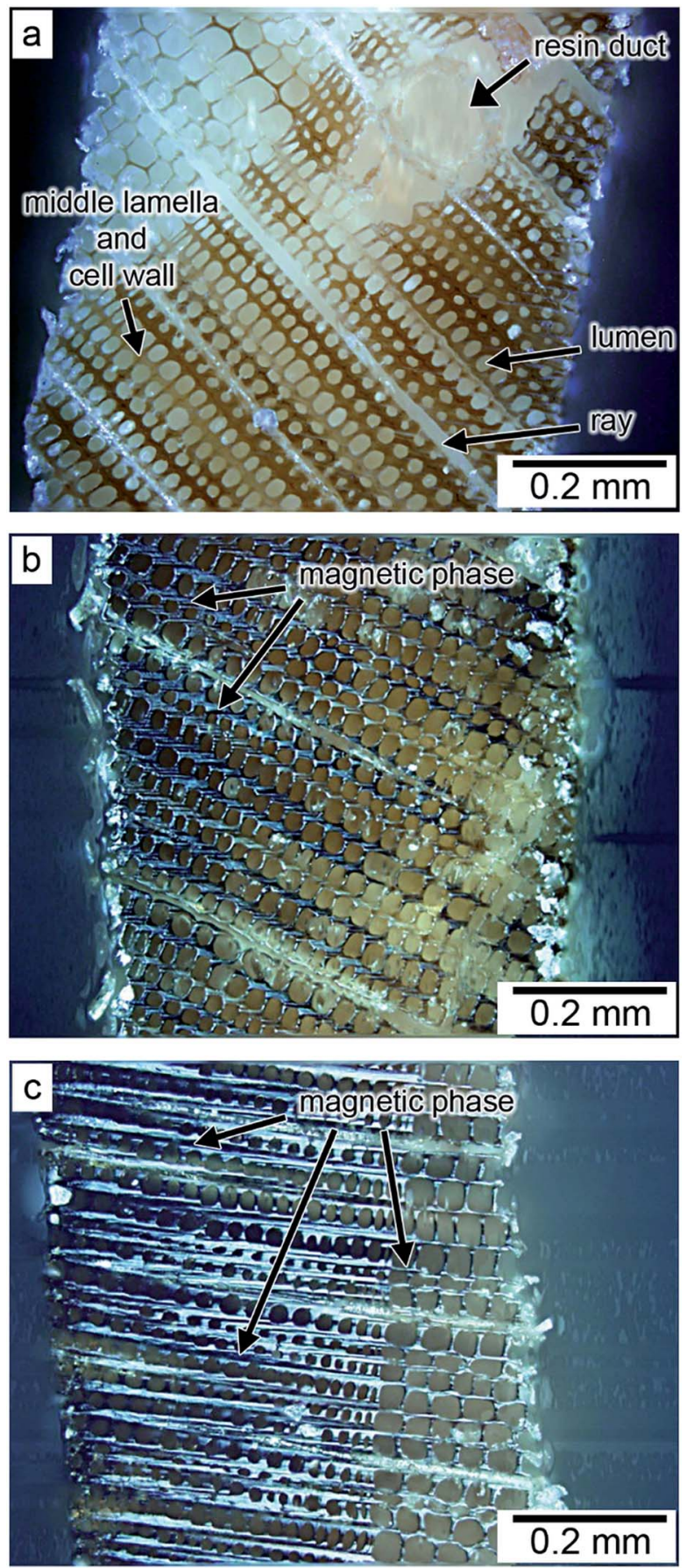

Fig. 2 Optical microscopy pictures of cross-sections of a modified wood veneer specimen. (a) Unmodified wood veneer ( $v-U$ ); (b) wood veneer modified with $c a$. 8 wt $\% \mathrm{Fe}_{3} \mathrm{O}_{4}\left(v-\mathrm{Fe}_{3} \mathrm{O}_{4}\right)$; and (c) wood veneer modified with ca. 20 wt\% $\mathrm{Fe}_{3} \mathrm{O}_{4}\left(v-\mathrm{Fe}_{3} \mathrm{O}_{4}\right)$.

suggesting that there is indeed a higher concentration of particles that have precipitated in the wood structure that were exposed to the more concentrated metal ion salt solutions (Fig 2c). Therefore, the diffusion of the salt solution in the wood structure during impregnation was not hindered to a large degree in the more concentrated iron solution, which was consistent with the use of
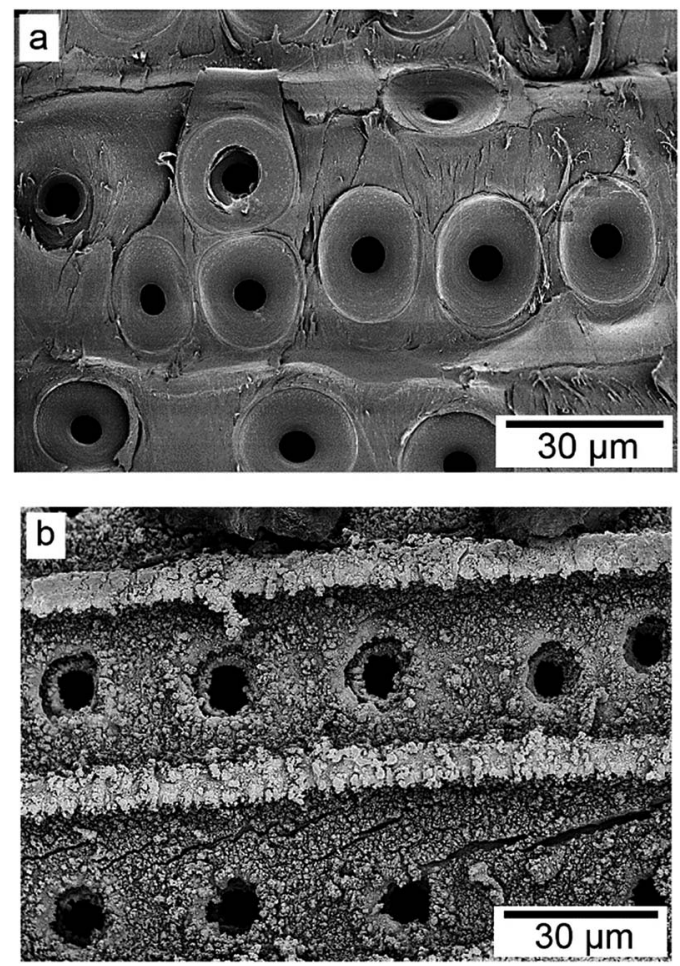

Fig. 3 Lumen walls of the wood containing pores (a) $v-U$ and (b) $v-\mathrm{Fe}_{3} \mathrm{O}_{4}$

acid to lower the complex formation of the metal ions at lower $\mathrm{pH}^{23}$

When observed by SEM (Fig. 3 and 4), the particles coat the lumen wall and were observed to alter the appearance of the wood structure. The lumen walls have pores that transport water between cells. These pores are shown in the overview picture of Fig. 3a and b. The particles have coated these pores and the walls of the lumen.

Fig. 4a shows a magnified view of the internal pore wall for the unmodified sample, whereas magnetite, cobalt and manganese ferrite nanoparticles and their adhesion to the internal pores and the walls of the lumen are depicted in Fig. 4b-c. The morphology of the particles varies with magnetite $\left(\mathrm{Fe}_{3} \mathrm{O}_{4}\right.$-particles) being more globular or spherical in form (Fig. 4b), the cobalt ferrites $\left(\mathrm{CoFe}_{2} \mathrm{O}_{4}\right.$-particles) appearing more plate like with jagged/facetted edges and a larger range of particle sizes on the lumen wall (Fig. 4c), and the manganese ferrite $\left(\mathrm{MnFe}_{2} \mathrm{O}_{4}\right.$-particles) being more platelike with rounder edges and more homogeneous particle size on the inside of the lumen wall (Fig. 4d). It appears that most precipitated particles are about $100-300 \mathrm{~nm}$ in size. A defined layer cannot be deciphered on the lumen wall, but in the SEM EDX pictures, this appears to be $1-2 \mu \mathrm{m}$ in thickness in the early wood and $0.5 \mu \mathrm{m}$ in the late wood. It is possible this is due to the fact that the late wood can take up more of the solution, leaving a less concentrated solution in the lumen in comparison to the thinner cell walls in the early wood. It is noted that the morphologies of the cobalt and the manganese ferrite phase are very different from the 

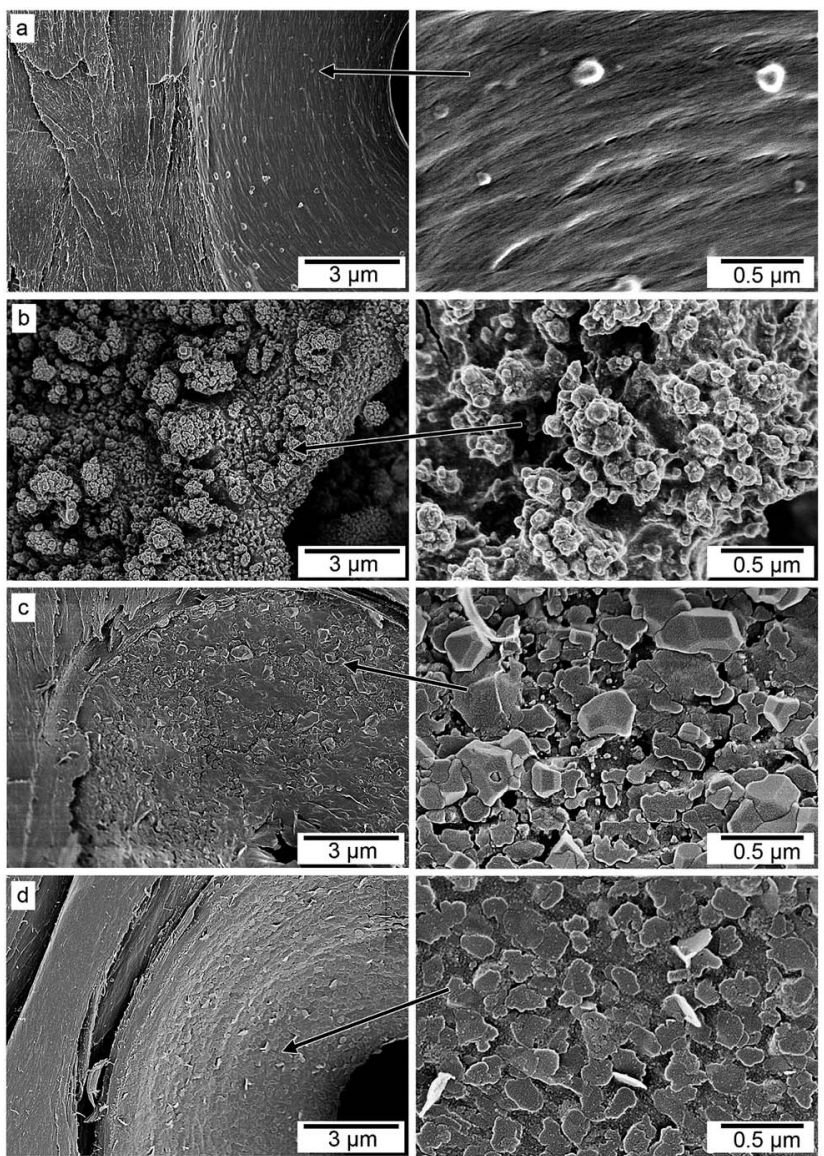

Fig. 4 Morphology of a particles on a pore connecting wood tracheids. in (a) untreated, (b) $v-\mathrm{Fe}_{3} \mathrm{O}_{4}$, (c) $v-\mathrm{CoFe}_{2} \mathrm{O}_{4}$, and (d) $\mathrm{v}-\mathrm{MnFe}_{2} \mathrm{O}_{4}$

morphologies previously reported on these systems as prepared in absence of templates, which normally result in cubic/spherical particles. These differences are likely due to both the inherent rate of crystal formation in the confined salt solution volumes within the pores, and the organization of metal salt precursors in the wood template under the heated aqueous environment.

\section{Determination of the presence of magnetic particles absorbed} in the wood structure

By SEM EDX, the elemental analysis of the untreated wood (Fig. 5, Table 2) can be determined in the middle lamella region (point 1 in Fig. 5b), the cell wall region (point 2 in Fig. 5 b), and inside the surface of the lumen wall (point 3 in Fig. 5b). From this data it can be determined that the main elements observed in untreated wood were carbon and oxygen, with similar values of both in all areas of the wood structure.

The cross section of the $\mathrm{v}-\mathrm{Fe}_{3} \mathrm{O}_{4}$ wood veneer sample was analyzed in the same manner by SEM EDX. These resulted in the detection of not only carbon and oxygen, but also iron. From the cross section of the sample, there is observed to be a region of late wood that is denser and a region of early wood that has a

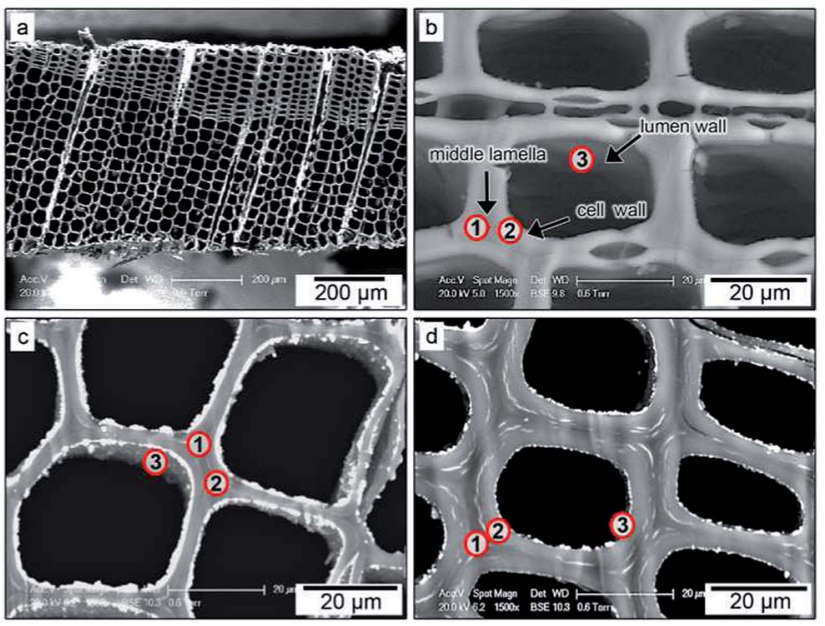

Fig. 5 SEM micrographs of the cross section of untreated wood (a and b), and $v-\mathrm{Fe}_{3} \mathrm{O}_{4}$ modified (c) early wood, (d) late wood.

less dense structure. The elemental analysis was analyzed in each type of structure to determine if the magnetic particles were more abundant in one than another. It was observed by backscattering electron mode that the magnetic particles appear as a white layer on the inside of the lumen walls, and also in the voids between the cell wall and middle lamella. There appear to be more void deposits and irregular deposits in the late wood compared to the early wood with a single deposit between the cell wall and middle lamella interface. The thicker layer of particles observed in the early wood could be a result of the larger lumen size that can hold more solution per cell to allow for more particles to precipitate out compared to late wood. Further, looking at the results of the elemental analysis, there is always a higher wt $\%$ of iron in the three different regions of the early wood structure compared to the late wood (Table 2). This could be due to the overall less dense structure of the wood and since it was faster growing, possibly with less dense structure.

\section{The weight percent gain, water uptake, and leaching of the modified wood}

The amount of magnetic particles in the wood structure was determined by thermal gravimetric analysis in an oxygen environment. This burned away the wood completely, leaving behind the magnetic particles. This was performed before and after leaching in water for 14 days (Fig. 6a and b). The initial weight loss before $200{ }^{\circ} \mathrm{C}$ is due to water loss and was accounted for in the calculations. Further, the magnetic particles lose about $14 \mathrm{wt} \%$ at $750{ }^{\circ} \mathrm{C}$, likely due to side products and impurities of the magnetic salt formation, and this was also accounted for in calculating the WPG values.

The water uptake after 14 days was determined to be almost the same for all samples, modified or unmodified at around 140 wt $\%$. Further, expansion of the wood with water uptake was not significantly affected with addition of magnetic particles as measured by taking the dimensions of the wood before and after treatment. This lack of effect of the modification on water 
Table 2 SEM EDX values of carbon and oxygen in points 1, 2, and 3 in Fig. $5 a-c$ unmodified $=v-U$ and modified $=v-\mathrm{Fe}_{3} \mathrm{O}_{4}$

\begin{tabular}{llll}
\hline Cross section & $\begin{array}{l}\text { Carbon wt\%, } \\
\text { unmod./mod., EW(LW) }\end{array}$ & $\begin{array}{l}\text { Oxygen wt\%, } \\
\text { unmod./mod., EW(LW) }\end{array}$ & $\begin{array}{l}\text { Iron wt\%, } \\
\text { unmod./mod., EW(LW) }\end{array}$ \\
\hline Middle lamella - pt 1 & $65 / 39(55)$ & $35 / 39(31)$ & $-/ 11(6)$ \\
Cell wall - pt 2 & $67 / 47(55)$ & $33 / 33(34)$ & $-/ 10(4)$ \\
Lumen wall - pt 3 & $59 / 39(51)$ & $40 / 23(32)$ & $-/ 27(8)$
\end{tabular}

a.)

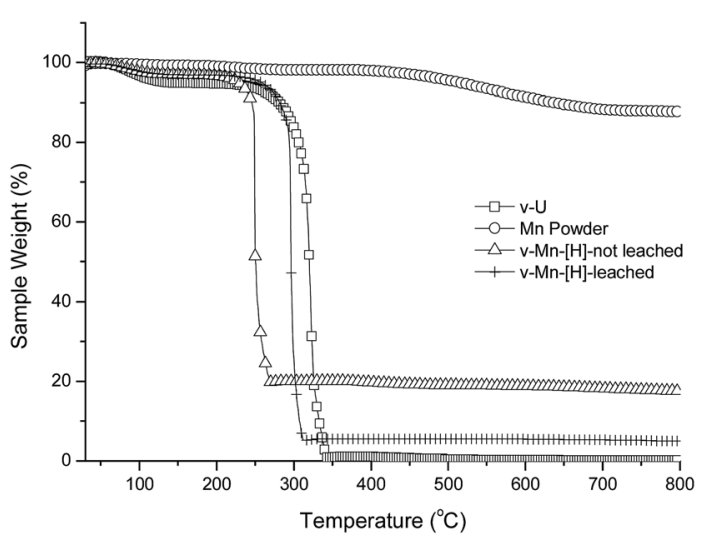

b.)

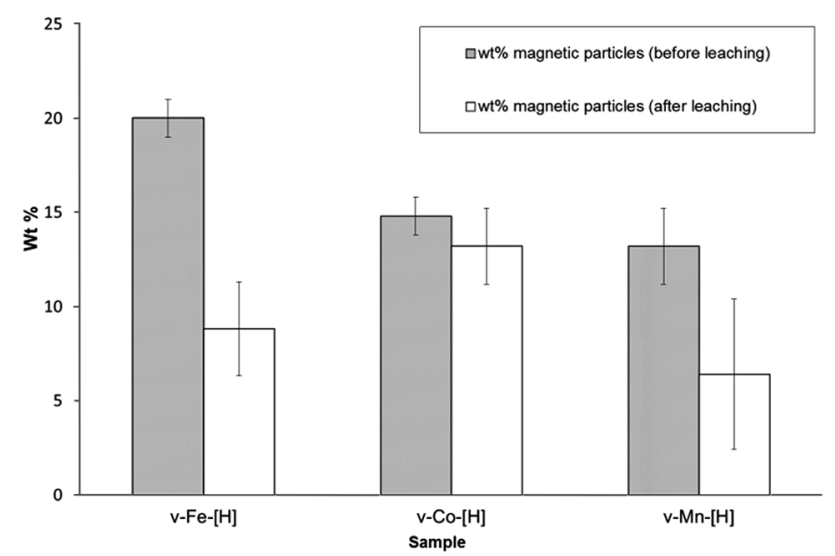

Fig. 6 (a) TGA plot of samples and the observance of remaining magnetic particles at $750{ }^{\circ} \mathrm{C}$. (b) Summary of Weight Percent Gain (WPG) and leaching of the unmodified and modified wood veneer specimen.

uptake and bulking of the wood implies that the magnetic particles do not replace the space that the wood uses for water uptake in its structure (mostly the cell wall), even though the presence of the particles are detected throughout the structure as is presented in the EDX section of this paper.

\section{Magnetic character of the particles and modified wood}

Hysteresis measurements (Fig. 7) confirmed that the uptake of the magnetic material was consistent with the TGA measurements. Iron and manganese ferrites are in general magnetically soft, which means that the material easily changes its magnetization due to an external magnetic field. This results in very thin, but tall hysteresis loops. Soft magnetic properties are used in electrical motors and generators. Cobalt ferrite has instead

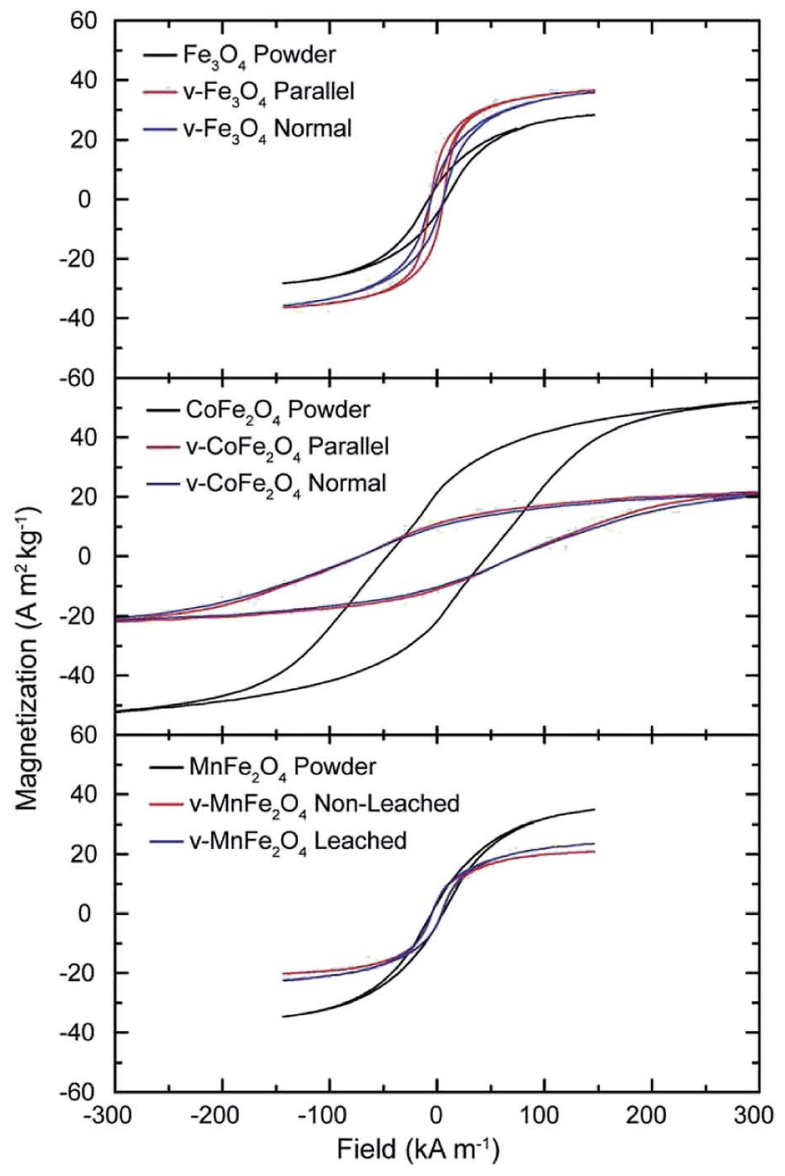

Fig. 7 Magnetic hysteresis measurements of modified veneers and powder compacts demonstrating the big difference in magnetic properties between soft and hard magnetic materials. It also shows the effects of fibre orientation and leaching: (a) iron ferrite $\mathrm{Fe}_{3} \mathrm{O}_{4}$, (b) manganese ferrite $\mathrm{MnFe}_{2} \mathrm{O}_{4}$, (c) cobalt ferrite $\mathrm{CoFe}_{2} \mathrm{O}_{3}$. Magnetisation values are normalised with respect to amount of magnetic material.

the opposite property: it is magnetically hard with a wide loop. This results in permanent magnetization and due to this property, it is often found in applications such as turbines. ${ }^{29}$

The iron ferrite loaded wood veneer sample, v- $\mathrm{Fe}_{3} \mathrm{O}_{4}$, Fig. 7a, showed a slight but clear directional dependence due to whether the applied field is parallel or normal to the fiber direction. The hysteresis loop is distinctively steeper when the applied field is parallel to the fiber direction, suggesting that the magnetic particles along this direction are in closer proximity to one another. 
The cobalt ferrite wood veneer samples, v-CoFe $\mathrm{O}_{4}$, Fig. 7b, showed insignificant directional dependence, however a slight but distinct wider loop is observed for the wood veneer samples compared to the compact powder. We suggest that this increase is due to that the particles are better separated as precipitated in the wood samples than in the compact powder.

The manganese ferrite wood veneer samples, v- $\mathrm{MnFe}_{2} \mathrm{O}_{4}$, Fig. 7c, both unleached and leached, showed very little effect on the magnetic properties. This material is also the softest of all in our investigation. From this study, it is difficult to speculate how the particles are attached to the wood samples, either by physical or chemical interactions. According to Di Marco et al., agglomeration of iron oxide particles in the absence of a surface occurs mainly due to van der Waals forces. In the presence of a surface, it can be very difficult to evaluate a distinction between chemical or physical adsorption involving week charge transfer or hydrogen bonding. ${ }^{30}$ It is uncertain as to why the hard magnetic phase attaches more readily.

This data demonstrates that the wood samples can be modified with a range of both hard and soft magnetic particles and that the modified wood will take on the magnetic properties of the original magnetic material.

\section{Crystalline structure of the magnetic particles, alone and in the modified wood}

To determine if the crystal structure of the magnetic particles differed from formation in the veneers compared to in free solution, XRD was performed (Fig. 8). As a result of the low density of wood as a material, the depth of the measurement could be as high as a few hundred microns. ${ }^{31}$ Two major diffraction peaks were observed for wood alone at approximately $18^{\circ}$ and $22^{\circ}$, which correspond to the 101 and 002 crystal planes, respectively. The XRD plots show variation at the 002 diffraction peak $\left(2 \theta=22^{\circ}\right)$, which is associated with the crystalline region of the cellulose. The crystallinity increased after modification as indicated by the increased area under the peak at $22^{\circ}$, indicating hydrolysis of the amorphous region of the

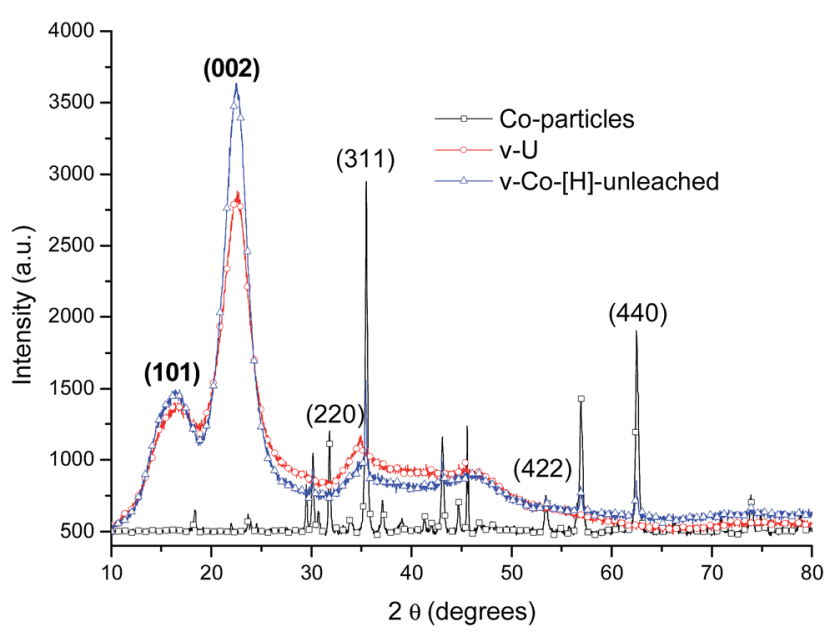

Fig. 8 WAXD spectra of $\mathrm{CoFe}_{2} \mathrm{O}_{3}$ samples with crystal planes from wood in bold. wood being hemicelluloses and a portion of the lignin with no significant effect on the crystallinity of the cellulose. ${ }^{32}$ The hydrolysis of hemicellulose by acid hydrolysis is well documented and has been shown to decrease the strength of wood and increase porosity. Since hemicellulose is always amorphous, this decreases the amorphous content of wood, thus making the crystalline area seem larger. Since $2 \mathrm{wt} \%$ is a fairly low amount of hydrolysis of the amorphous area of wood which is usually around $30-40 \mathrm{wt} \%$, there should not be a very large change in the wood structure in this case. Cobalt ferrite particles have diffraction peaks corresponding to the spinel structure of an orthorhombic cell with values of $2 \theta$ at $30.3^{\circ}, 35.6^{\circ}$, $53.3^{\circ}$ and $62.9^{\circ}$, corresponding to crystal planes (220), (311), (422) and (440). ${ }^{33}$ There appeared to be no difference in the main peaks of the crystal structure of the magnetic particles in comparison to those that deposited in the modified wood samples, indicating that the constrained environment of particle formation in the wood did not affect the type of crystal growth. Due to this lack of a difference in the crystal structure of the particles that deposited in the wood structure versus freely in solution, only the cobalt ferrite system is shown as an example.

\section{Conclusions}

This study presents a promising method to make threedimensional lattices of structured nanomaterials by using a wood template. It was found that it was possible to produce lightweight ferromagnetic functionalized wood materials in an inexpensive fashion by direct impregnation of the wood samples with iron/manganese/cobalt based salt solutions that were allowed to precipitate in situ in the cell walls of the wood. It was possible to functionalise wood throughout the structure with a high weight percent of particles from 15-20 wt\% as observed by TGA. These were not only adsorbed to the surface of the lumen, but also found throughout the cell wall and middle lamella and in higher amounts in early wood by SEM-EDX. The fiber direction and leaching did not significantly affect the coercivity of the modified wood samples. The crystal structure of the magnetic particles was determined to be the same in the wood structure as those formed in solution but the morphologies of the particles were different, presenting facetted shapes and flakes instead of cubes and spheres.

\section{Acknowledgements}

The Wallenberg Wood Science Centre is thanked for funding. Rodrigo Robinson is thanked for the assistance with SEM EDX and Andreas Fischer for his x-ray measurements.

\section{Notes and references}

1 H.-H. Yang, S.-Q. Zhang, X.-L. Chen, Z.-X. Zhuang, J.-G. Xu and X.-R. Wang, Anal. Chem., 2004, 76, 1316.

2 C. Pascal, J. L. Pascal and F. Favier, Chem. Mater., 1999, 11, 141. 
3 B. Z. Tang, Y. Geng, J. W. Y. Lam and B. Li, Chem. Mater., 1999, 11, 1581.

4 G. T. Rado, Rev. Mod. Phys., 1953, 25, 81.

5 A. K. Gupta and M. Gupta, Biomaterials, 2005, 26, 3995.

6 S. Laurent, D. Forge, M. Port, A. Roch, C. Robic, L. V. Elst and R. N. Muller, Chem. Rev., 2008, 108, 2064.

7 A. C. Balazs, T. Emrick and T. P. Russel, Science, 2006, 17, 1107.

8 R. T. Olsson, M. S. Hedenqvist, V. Ström, J. Deng, S. J. Savage and U. W. Gedde, Polym. Eng. Sci., 2011, 51, 862.

9 M. Takafuji, S. Ide, H. Ihara and Z. Xu, Chem. Mater., 2004, 16, 1977.

10 C. T. Yavuz, Science, 2005, 314, 964.

11 S. Galland, R. L. Andersson, M. Salajková, V. Ström, R. T. Olsson and L. Berglund, J. Mater. Chem. C, 2013, 1, 7963.

12 G. Korneva, H. Ye, Y. Gogotsi, D. Halverson, G. Griedman, J.-C. Bradley and K. G. Kornev, Nano Lett., 2012, 5, 879.

13 C. Chappert, H. Bernas, J. Ferré, V. Kottler, J.-P. Jamet, Y. Chen, E. Cambrill, T. Devolder, F. Rousseaux, V. Mathet and H. Launois, Science, 1998, 280, 1919.

14 C. Petit, A. Taleb and M. P. Pileni, J. Phys. Chem. B, 1999, 103, 1805.

15 S. Palacin, P. C. Hidber, J.-P. Bourgoin, C. Miramond, C. Fermon and G. M. Whitesides, Chem. Mater., 1996, 8, 1316.

16 M. Fang, V. Ström, R. T. Olsson, L. Belova and K. V. Rao, Appl. Phys. Lett., 2011, 99, 222501.

17 D. L. Leslie-Pelecky, Chem. Mater., 1996, 8, 1770.

18 R. H. Marchessault, P. Rioux and L. Raymond, Polymer, 1992, 33, 4024.

19 R. H. Marchessault, S. Ricard and P. Rioux, Carbohydr. Res., 1992, 224, 133.

20 R. T. Olsson, M. A. S. Azizi Samir, G. Salazar-Alvarez, L. Belova, V. Ström, L. A. Berglund, O. Ikkala, J. Nogués and U. W. Gedde, Nat. Nanotechnol., 2010, 5, 584.

21 S. Liu, L. Zhang, J. Zhou, J. Xiang, J. Sun and J. Guan, Chem. Mater., 2000, 20, 3623.

22 V. Ström, R. T. Olsson and K. V. Rao, J. Mater. Chem., 2010, 20, 4168.
23 R. T. Olsson, G. Salazar-Alvarez, M. Hedenqvist, U. W. Gedde, F. Lindberg and S. J. Savage, Chem. Mater., 2005, 17, 5109.

24 S. Trey, R. Olsson, V. Ström, L. Berglund and M. Johansson, The sixth European Conference on Wood Modification Proceedings, ed. D. Jones, H. Militz, M. Petric, F. Pohleven, M. Humar and M. Pavlic, 2012, pp. 413-418, ISBN 978961644353.

25 V. Merk, M. Chanana, N. Gierlinger, A. M. Hirt and I. Burgert, Hybrid wood materials with magnetic anisotropy dictated by the hierarchical cell structure, ACS Appl. Mater. Interfaces, 2014, 6, 9760-9767.

26 J. P. Jolivet, C. Chanéac and E. Tronc, Chem. Commun., 2004, 481.

27 S. Trey, J. Netrval, L. Berglund and M. Johansson, Electron beam polymerization method of poly(ethylene glycol) based wood impregnants, ACS Appl. Mater. Interfaces, 2010, 2, 3352 .

28 EN-84:1997 wood preservatives-accelerated ageing of treated wood prior to biological testing-leaching procedure, CEN, European Committee for Standardization.

29 M. Chinchilla, S. Arnaltes and J. C. Burgos, Control of permanent-magnet generators applied to variable-speed wind-energy systems connected to the grid, Energy Convers., 2006, 21, 130-135.

30 M. Di Marco, C. Sadun, M. Port, I. Guilbert, P. Coubreur and C. Dubernet, Physicochemical characterization of ultrasmall superparamagnetic iron oxide particles (USPIO) for biomedical application as MRI contrast agents, Int. J. Nanomed., 2007, 2, 609-622.

31 X-ray diffraction data sheet, http:// www.innovationservices.philips.com/materials-analysisxrd.pdf, accessed 2013-03-01, 2008, Koninklijke Philips Electronics N.V.

32 S. Panthapulakkal and M. Sain, J. Wood Chem. Technol., 2013, 33, 92.

33 G. E. Oliveira, J. E. S. Clarindo, K. S. E. Santo and F. G. Souza, Mat. Res., 2013, 16, 668. 